\title{
Global Epidemiology of Myopia
}

\author{
Saiko Matsumura, Cheng Ching-Yu, and Seang-Mei Saw
}

\section{Key Points}

- The prevalence of myopia in children is high in urban East Asian countries.

- The myopia and HM prevalence among young adults is much higher in East Asia than in Western countries.

- The burden of HM is huge because HM can cause PM changes and visual impairment.

- The prevalence of PM among adults has been relatively low, but it is likely to increase in future.

- It is important to develop public policies and preventive measures to retard the epidemic myopia.

\section{S. Matsumura}

Singapore Eye Research Institute, Singapore, Singapore

e-mail: matsumura.saiko@seri.com.sg

C. Ching-Yu

Singapore National Eye Centre, Singapore, Singapore

National University of Singapore, Singapore, Singapore

Duke-NUS Medical School, Singapore, Singapore

e-mail: chingyu.cheng@duke-nus.edu.sg

S.-M. Saw $(\bowtie)$

Singapore Eye Research Institute, Singapore, Singapore

National University of Singapore, Singapore, Singapore

Saw Swee Hock School of Public Health, National University of Singapore,

Singapore, Singapore

e-mail: ephssm@nus.edu.sg, saw.seang.mei@seri.com.sg 


\subsection{Introduction}

Myopia has become a significant global public health and socioeconomic problem [1-4]. Developed countries, especially among East Asia, have been faced with high prevalence of myopia and high myopia (HM) and the same trend has been shown in other parts of the world with less extent $[5,6]$. (The definition of myopia and HM is spherical equivalence (SE) of -0.50 diopters (D) or less and SE $-5.00 \mathrm{D}$ or -6.00 $\mathrm{D}$, respectively.) The prevalence of myopia and HM in young adults in urban area of East Asian countries has risen to $80-90 \%$ and around $20 \%$, respectively [7, 8]. According to a summary of 145 studies regarding the global prevalence of myopia and HM, there are approximately 1950 million (28.3\% of the global population) and 277 million (4.0\% of the global population) cases, and they are predicted to increase to 4758 million ( $49.8 \%$ of the global population) for myopia, and 938 million $(9.8 \%$ of the global population) for HM by 2050 [9].

Most cases of myopia are considered as a benign condition because vision is corrected with spectacles, contact lenses, or refractive surgery. However, severe cases of myopia are associated with the risk of irreversible vision impairment and blindness due to pathological changes in retina, choroid, and sclera. One study has shown that $25 \%$ of HM will develop pathologic myopia (PM) and $50 \%$ of those with PM will have low vision as older adults. Thus, HM and PM are likely to increase drastically in the older generation. Based on the global prediction of HM on 2050, PM may increase to over 200 million in future [9]. Treatment strategies against PM have not been effective and costly [10]. Considering the burden of PM in the future, it is important to develop public policies and preventive and early interventional measures to retard the epidemic myopia. In this chapter, we summarize data on the prevalence of myopia and HM in different generations and the prevalence of PM from recent epidemiological studies.

\subsection{Prevalence of Myopia in Children}

In children, cycloplegic refraction is a common procedure to measure refractive error because children have a possibility to have an overestimation of myopic refraction, due to increased tone of the ciliary muscle and a constant accommodative effort during the examination, and makes the refraction overestimated approximately over -1 to $-2 \mathrm{D}[11,12]$. Many population-based studies on children have proved that the prevalence of myopia is higher in urbanized East Asian countries. In surveys of 12-year-old children, the prevalence of myopia is higher in Singapore (62.0\%) [13], Hong Kong (53.1\%) [14], and Guangzhou, China $(49.7 \%)$ [15] than in the United States $(20.0 \%)$ [16], Northern Ireland $(17.7 \%)$ [17], Australia (11.9\%) [18], urban India (9.7\%) [19], Nepal (16.5\%) [20], and Cambodia (6.0\%) [21]. We summarized the prevalence of myopia among children in population studies using cycloplegic refraction between Asian countries (Table 2.1) and non-Asian countries (Table 2.2). 


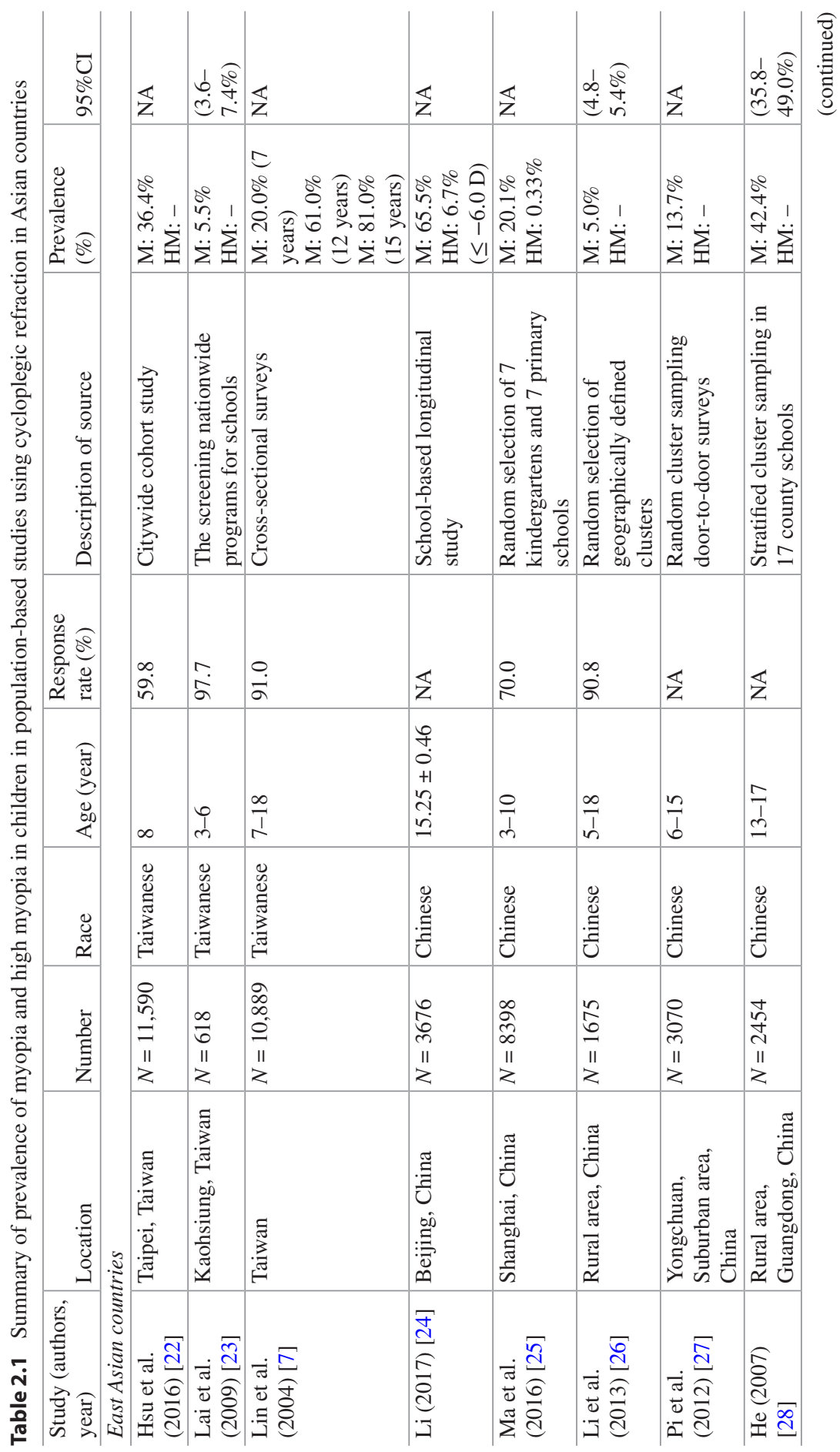




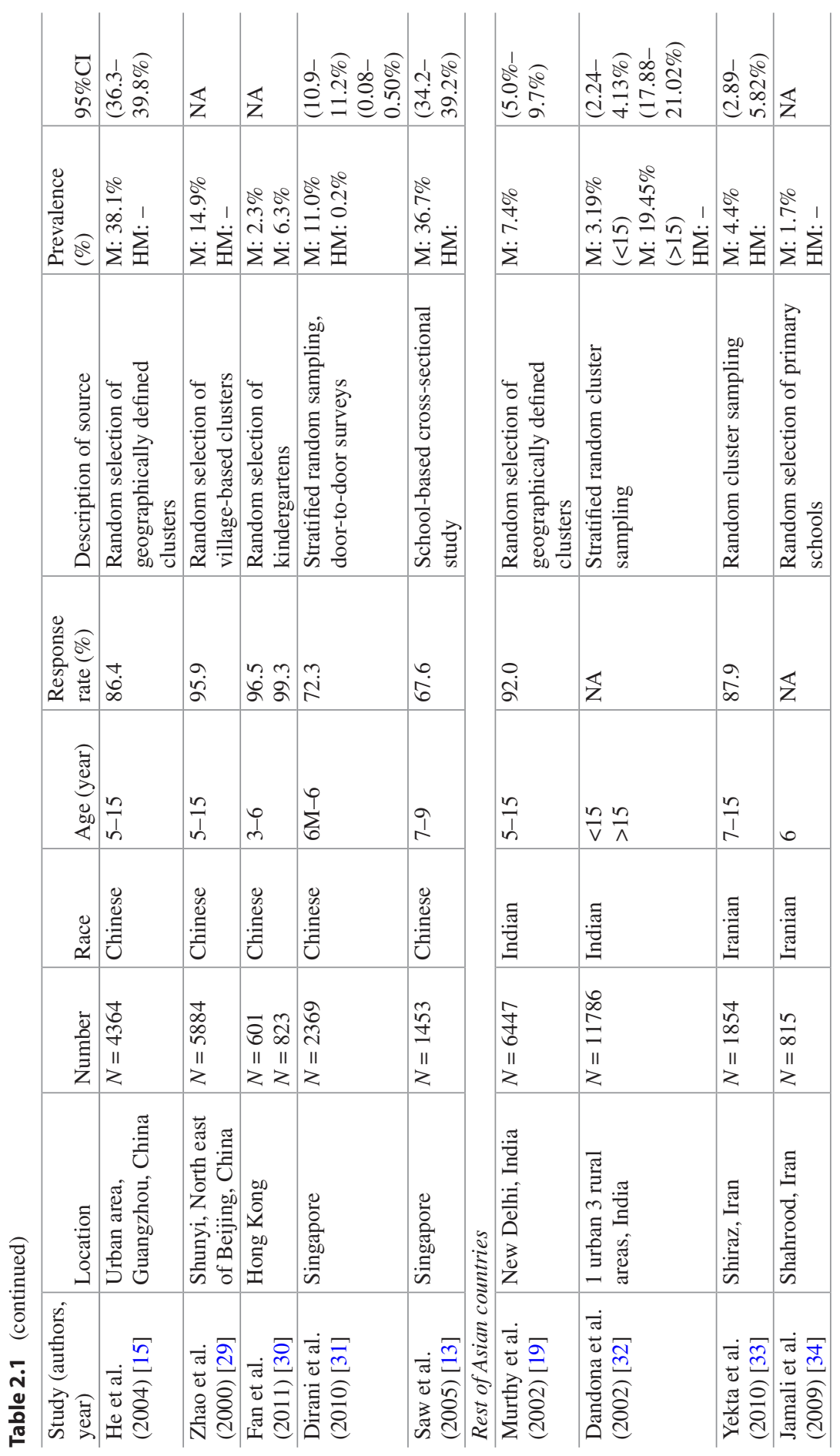




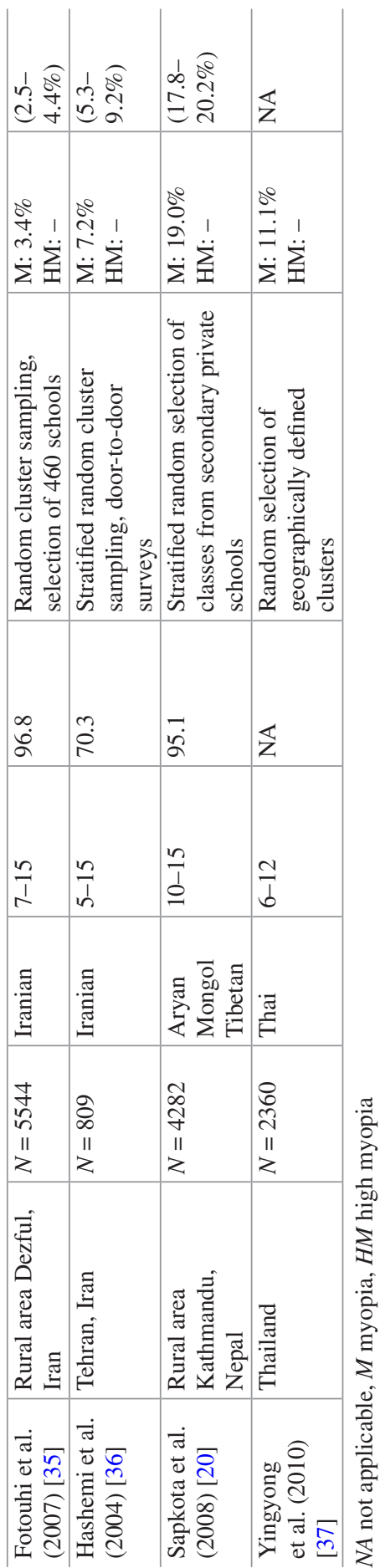




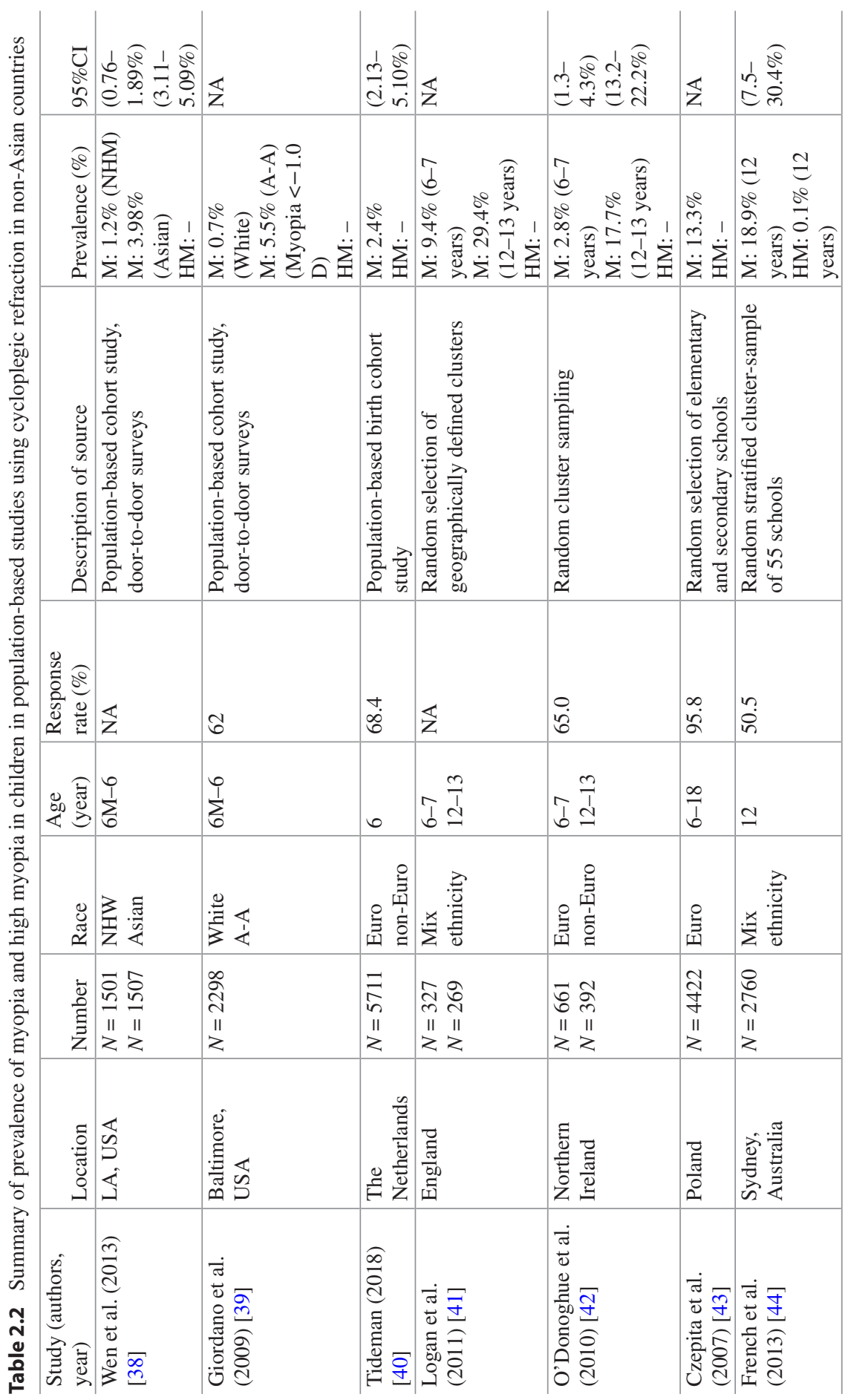




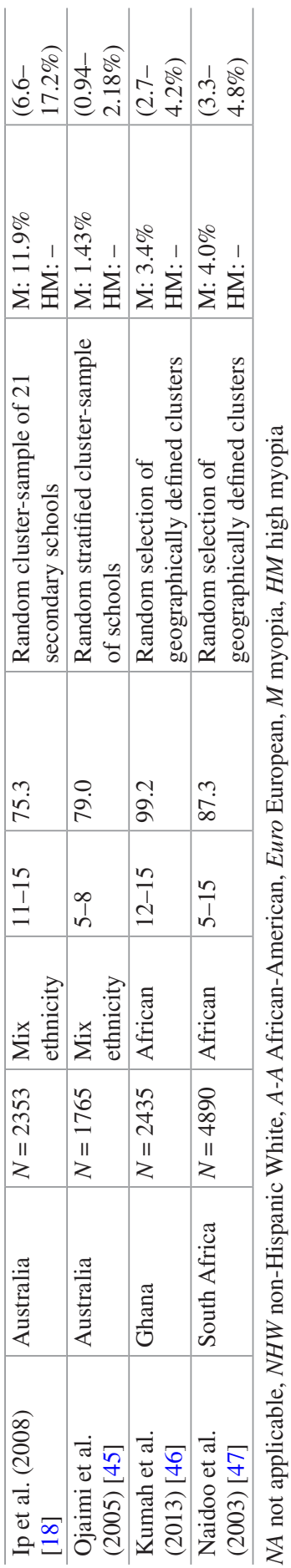




\subsubsection{Asian Countries}

\subsubsection{East Asian Countries and Singapore}

Taiwanese school children have the highest prevalence of myopia among all school children worldwide. The prevalence of myopia among 8-year-old children is $36.4 \%$ in Taiwan [22], followed by $34.7 \%$ in Singapore [13], 30.8\% in Shanghai [25] and $14.0 \%$ in Malaysia [48]. Lai et al. reported that the prevalence of myopia among 618 preschool Taiwanese children were also as high as $3.0 \%, 4.2 \%, 4.7 \%$, and $12.2 \%$ in the age groups of $3,4,5$, and 6 years, respectively [23]. A nationwide myopia survey in Taiwan showed that the prevalence of myopia among 7-year-olds increased from $5.8 \%$ in 1983 to $21 \%$ in 2000 . At the age of 12 , the prevalence of myopia was $36.7 \%$ in 1983 increasing to $61 \%$ in 2000 , corresponding figures for 15 -year-olds being $64.2 \%$ and $81 \%$, respectively [7]. In China, Ma et al. reported that the prevalence of myopia in Shanghai was $20.1 \%$ among 3-year-old to 10 -year-old children. They also showed that the prevalence increased dramatically from 5.2\% in 6-yearold children and $14.3 \%$ in 7-year-old children to $52.2 \%$ in 10-year-old children [25]. In the urban city of Guangzhou, the prevalence of myopia was $7.7 \%$ in 7-year-old, $30.1 \%$ in 10-year-old, and $78.4 \%$ in 15-year-old children, with an overall prevalence of $38.1 \%$ among 4364 children aged 5-15 years [15]. In a rural area of Beijing, Zhao et al. reported that the prevalence of myopia among school children aged 5-7 and $14-15$ years were $1.2 \%$ and $38.8 \%$, respectively, with an overall prevalence of $14.9 \%$ among 5884 children aged 5-15 years [29]. In a suburban area, the prevalence of myopia among 3070 school children aged $6,7,10$, and 14 years was $0.42 \%$, $1.92 \%, 9.4 \%$, and $28.8 \%$, respectively [27]. In another rural area of northern China, the prevalence of myopia among 1675 school children aged 5-9, 10-14, and 15-18 years was $0.9 \%, 4.5 \%$, and $8.2 \%$, respectively, with an overall prevalence rate of $5.0 \%$ [49]. In Hong-Kong, 2 population-based surveys were conducted in children aged 3-6 years during 1996-1997 and 2006-2007, which revealed that prevalence of myopia increased 2.3-6.3\% in a decade [30]. In Singapore, the school-based population study of the Singapore Cohort Study of Risk factors for Myopia (SCORM) showed that the prevalence of myopia was $29.0 \%$ in 7-year-olds, $34.7 \%$ in 8-yearolds, and 53.1\% in 9-year-olds [50]. In younger ages from 6 months to 6 years, the Strabismus, Amblyopia, and Refractive Error in Singapore (STARS) Study reported that the prevalence of myopia was $11.0 \%$ in Chinese children [31].

\subsubsection{Rest of Asian Countries}

On the other hand, the prevalence of myopia is generally lower in other countries in Asia. In India, 6447 school children aged 5-15 years had $7.4 \%$ of the myopia prevalence in an urban population in New Delhi [19]. A population-based cross-sectional study was conducted among children in 1 urban and 3 rural areas. It reported that the prevalence of myopia among children $\leq 15$ years of age and $>15$ years of age was $3.2 \%$ and $20.0 \%$, respectively [32]. In Iran, the prevalence of myopia among 1854 school children aged 7,10, and 14 years were $1.7 \%, 2.4 \%$, and $7.6 \%$, respectively, with an overall prevalence rate of $4.4 \%$ among 7 -year-old to 15 -year-old children in Shiraz [33]. In 4282 Nepalese secondary school children aged 10-15 years, 
the myopia prevalence was ranged from $10.9 \%$ in 10 -year-olds to $27.3 \%$ in 15 -yearolds [20]. In Thailand, the prevalence of myopia was $11.1 \%$ in 2360 children aged 6-12 years [37].

\subsubsection{Non-Asian Countries}

Nowadays, a rise of the myopia prevalence has also been shown in non-East-Asian countries that previously were only mildly or moderately affected, such as the UK, Australia, and the United States, although the prevalence is still lower than that in Asian countries. In the United States, the prevalence of myopia among 6-month-old to 6-year-old children was $1.20 \%$ and $3.98 \%$ in 1501 non-Hispanic White and 1507 Asian ethnicity children, respectively, as per the Multi-Ethnic Pediatric Eye Disease Study [38]. In the Baltimore Eye Study, the prevalence of myopia (SE $<-1.00 \mathrm{D})$ was $1.2 \%$ in Whites, $6.6 \%$ in African-Americans among children aged 6 years, and an overall prevalence among 6-month-old to 71-month-old children was $0.7 \%$ and $5.5 \%$ in 1030 Whites and 1268 African-Americans, respectively [39]. Although few reports have been published on the prevalence of myopia in children in Europe, regional differences from country to country were shown even within the same geographical area. In England, the Aston Eye Study (AES) reported that the prevalence was 9.4\% among children aged 6-7 years, and $29.4 \%$ among children aged $12-13$ years, whereas the prevalence was $2.8 \%$ and $17.7 \%$ among children in the same age groups in Northern Ireland $[17,41]$. In the Netherlands, the myopia prevalence rate was as low as $2.4 \%$ in 5711 children aged 6 years [40]. In Poland, the myopia prevalence was lower: $2.0 \%$ in 6-year-old, $8.4 \%$ in 8-year-old, and $14.7 \%$ in 12 -year-old children [43]. In Australia, the Sydney Myopia Study (SMS) reported that myopia was present in $1.43 \%$ in 1765 children aged 7 years, with $0.79 \%$ in European children and $2.73 \%$ in other ethnicity children [45]. The Sydney Adolescent Vascular and Eye Study (SAVES) reported the myopia prevalence to be $18.9 \%$ among 12 -year-old children, with 52.5\% in East Asian, 8.6\% in European Caucasian, and 12.0\% in other ethnicity groups [44]. However, these ethnic differences may not be based solely on genetic differences. Studies on migrant populations suggest that the prevalence of myopia among Asian children living in non-Asian countries such as Australia is not as high as those living in East Asian countries [51]. Finally, in population-based studies, the lowest prevalence appears to be in Africa. The prevalence of myopia was 3.4\% in 12-year-old to 15-year-old children in Ghana and $4.0 \%$ in 5-year-old to 15-year-old children in South Africa [46].

\subsubsection{Urban and Rural Areas}

Collectively, there are significant differences in the prevalence of myopia between urban areas and rural areas. In China, the prevalence of myopia was $38.1 \%$ in children aged 5-15 years in urban area, Guangzhou, whereas the prevalence of myopia was 5.0\% in children aged 5-18 years in rural area. In an urban area, 
Tehran, the prevalence of myopia was $7.2 \%$ in 809 children aged 5-15 years in the Tehran Eye Study, while a rural area, Dezful, had a lower prevalence of myopia which was $3.4 \%$ in children aged $7-15$ years $[35,36]$. A recent meta-analysis found a 2.6 times higher risk of developing myopia in children of urban residence compared with those who lived in rural areas [52]. These differences in the myopia prevalence among children may be caused by a rigorous education system which children especially living in urbanized are exposed to. Especially in Eastern Asian countries, academic success is important, and most children are enrolled in competitive, academically oriented schooling at a very early age [51]. It is influenced by enduring patterns of behavior and cultural attitudes that may result in the myopic environmental factors, such as higher levels of more intense near-work and lower levels of outdoor activity.

In summary, the prevalence of myopia in children is higher in East Asian countries (49.7-62.0\% among 12-year-old children) compared with non-Asian countries and other Asian countries (6.0-20.0\%). The prevalence of myopia has remained consistently high among Chinese children in urban settings, but the evidence does not support the idea that it is caused by purely genetic difference [53]. The association of an urbanized setting with high myopia rates is likely to be influenced by possible modifiable risk factors such as near-work and outdoor time.

\subsection{Prevalence of Myopia and HM in Teenagers and Young Adults}

\subsubsection{East Asian Countries}

The prevalence of myopia in young adults is more than $80 \%$ in urbanized East Asian countries (Table 2.3). A remarkable increase in the myopia and HM prevalence was seen in the past decades. In China, Chen et al. conducted a 15-year populationbased survey using noncycloplegic autorefraction to investigate trends in the prevalence of myopia among 43,858 high school students in Fenghua city, eastern China, from 2001 to 2015. The overall prevalence of myopia and HM increased from $79.5 \%$ to $87.7 \%$ and $7.9 \%$ to $16.6 \%$, respectively, during the 15 -year period [54]. In Shandong, another city in eastern China, the prevalence of myopia and HM using cycloplegic autorefraction in school children aged 17 years was $84.6 \%$ and $13.9 \%$, respectively [55]. A cross-sectional study among 5083 university students in Shanghai showed that $95.5 \%$ were myopic and $19.5 \%$ were high myopic (SE $<-6.0$ D) [56]. In Korea, the prevalence of myopia and HM (SE <-6.0 D) using cycloplegic autorefraction was higher in an urban population (96.5\% and $21.6 \%$ ) [8], compared to a rural population (83.3\% and 6.8\%) [26], among 19-year-old males in military conscripts. In Taiwan, the prevalence of myopia and HM (SE $<-6.0$ D) was $86.1 \%$ and $21.2 \%$, respectively, in males aged $18-24$ years in military conscripts [57]. In Singapore, the overall myopia and HM prevalence in 28,906 young males aged 16-25 years increased from $79.2 \%$ and $13.1 \%$ in $1996-1997$ to $81.6 \%$ and $14.7 \%$ in 2009-2010, respectively [58]. 


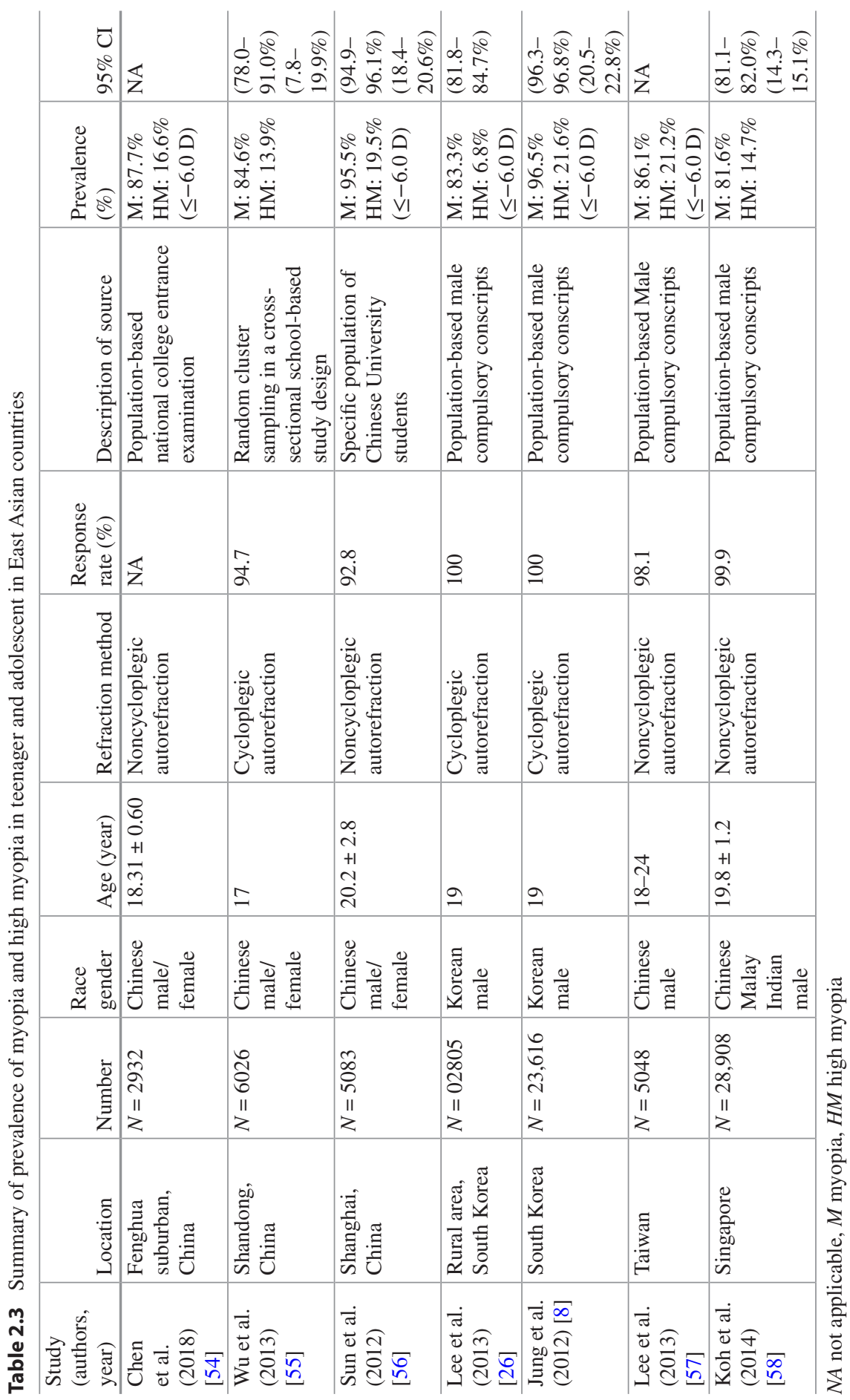




\subsubsection{Rest of East Asian Countries}

In contrast to the uniformly high prevalence in Eastern Asian countries, the prevalence of myopia and HM in young adult populations in other countries varies among different ethnicity and geography (Table 2.4). In Israel, a 13-year series of population-based prevalence survey was conducted on young adults aged 16-22 years during the years 1990-2002. The overall prevalence of myopia and HM (SE <-6.0 D) using noncycloplegic autorefraction increased from $20.3 \%$ and $1.7 \%$ in 1990 to $28.3 \%$ and $2.05 \%$ in 2002, respectively [59]. In the Tehran Eye Study, the prevalence of myopia using cycloplegic autorefraction was $29.3 \%$ among young adults aged 16-25 years [36]. In Australia, the prevalence of myopia was $20.4 \%$ in a population-based cohort using cycloplegic autorefraction in mostly White subjects aged 19-22 years [60]. In the Sydney Adolescent Vascular and Eye Study (SAVES), myopia was present in 30.8\%, with $59.1 \%$ in East Asian, $17.7 \%$ in European Caucasian, and $34.9 \%$ in other ethnicity group; and HM (SE <-6.00 D) was present in $1.9 \%$ among 17-year-old young adults [44]. In Europe, the prevalence of myopia and HM (SE <-6.50 D) among 4681 Danish conscripts was $12.8 \%$ and $0.3 \%$, respectively [61]. A population-based study in Norway reported that $35.0 \%$ were myopic among 1248 young adults aged 20-25 years [62]. In the United States, the myopic prevalence rate was $27.7 \%$ in young adults aged 18-24 years [63].

As shown above, the myopia prevalence among young adults in East Asia is much higher than in Western countries. This is most likely reflecting the higher myopia prevalence among school children in Eastern Asia and can be further accelerated by their education system. This age population usually spend much time in study and are expected to achieve high scores for competitive college entrance examination, especially in Asia. In one study conducted in China, the prevalence of myopia in postgraduates was higher than in undergraduates [56], suggesting that associated factors, such as higher school achievement and prolonged near-work and less outdoor time, might contribute to the increasing prevalence of myopia [51]. We summarized the myopia prevalence in East Asian countries (Table 2.3) and rest of East Asian countries (Table 2.4). When comparing the results, we must be cautious because some conscript-based studies investigated only men, and conducted eye examination without cycloplegic refraction, which may make the refraction overestimated approximately over $-0.50 \mathrm{D}$ in younger adults [64].

\subsection{Prevalence of Myopia and HM in Adults}

In adults, the prevalence rates of myopia vary widely with age reflecting the hyperopic shift by aging in older generations. According to the results from the Beaver Dam Eye Study, the prevalence of myopia was likely to decrease with age among individuals aged above 43 years [65]. Wong et al. showed that the highest prevalence of myopia was in the age group of 40 years and above 70 years among ChineseSingaporean adults aged 40-81 years old [66]. It suggested that the prevalence in elderly adults older 70 years could be overestimated due to lens nuclear sclerosis 


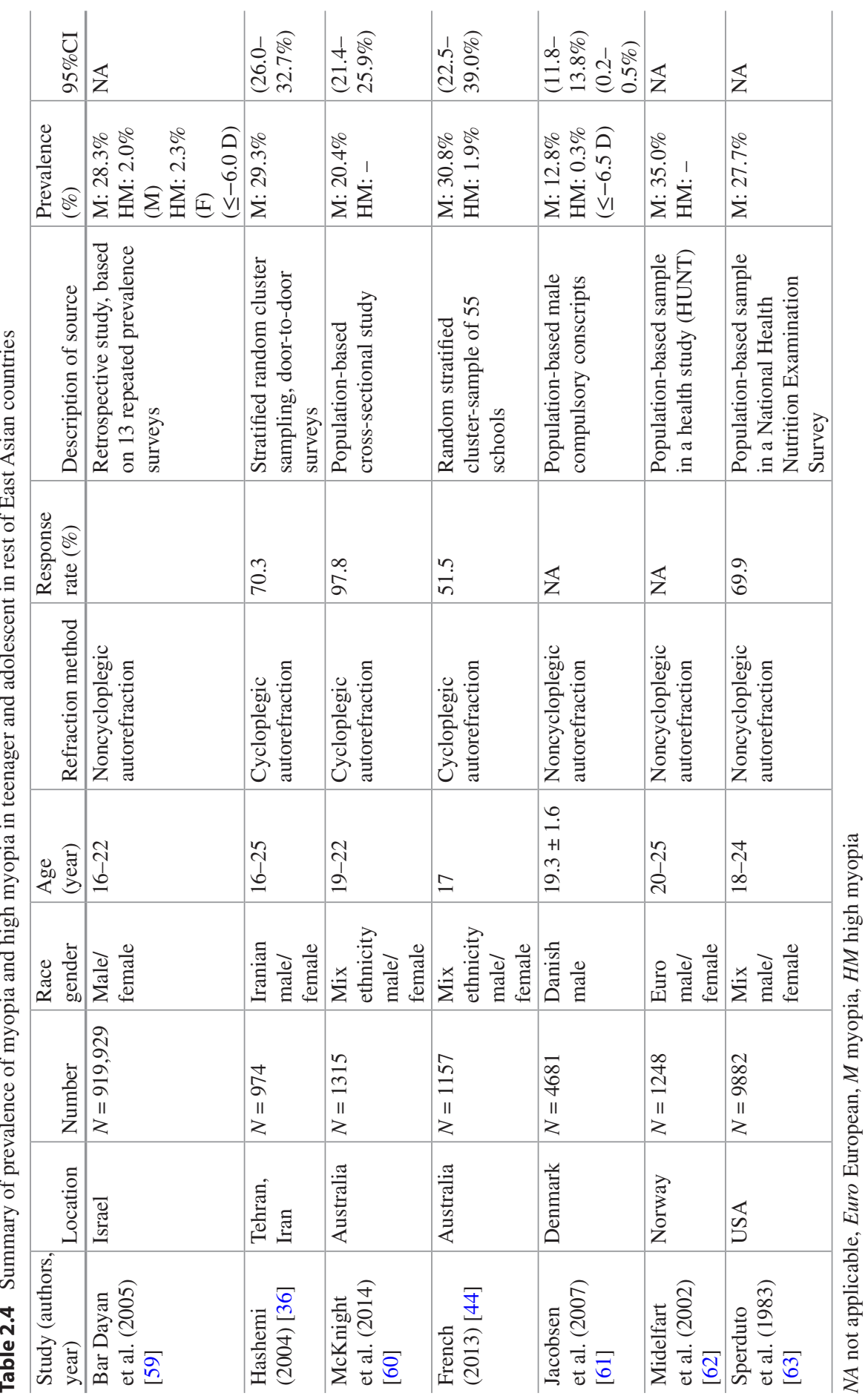




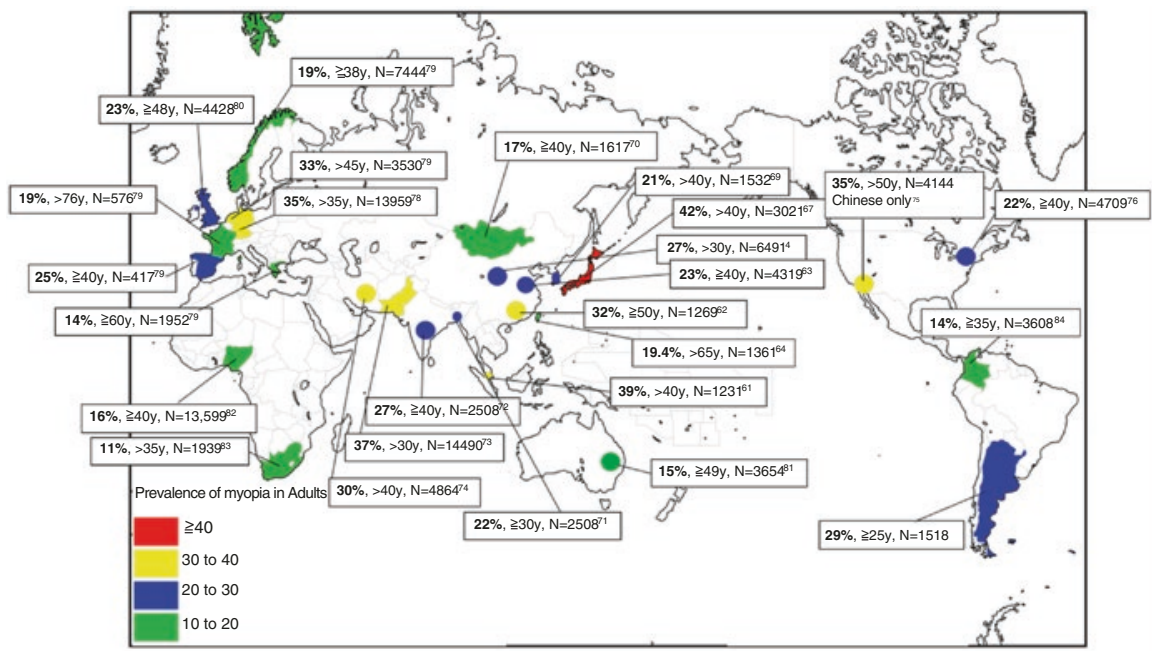

Fig. 2.1 Reported prevalence of myopia in adult population based on population studies

inducing refractive myopia. Population-based data indicate that Asian adult population is more susceptible to myopia compared with similarly aged western population. However, compared to the prevalence of myopia in children, the regional difference is not obvious in adults. We summarized the prevalence of myopia in adult population-based studies in the world (Fig. 2.1). It must be noted that there is lack of consensus in definitions of myopia and HM, and the definition varies among studies and that there is a difference of age population affecting by nuclear cataract, thus not directly comparable among different studies.

\subsubsection{Asian Countries}

\subsubsection{East Asian Countries}

In China, the prevalence of myopia and HM (SE <-6.0 D) was $32.3 \%$ and $5.0 \%$, respectively, in 1269 adults aged 50 or more years in the Liwan Eye Study [67] conducted in an urban city of Guangzhou. In rural areas, $26.7 \%$ were myopic and $1.8 \%$ were high myopic in 6491 adults aged 30 or more years in the Handan Eye Study [4]. The Beijing Eye Study reported that the myopia and HM (SE <-6.0 D) prevalence was $22.9 \%$ and $2.6 \%$, respectively, in 4319 adults aged 40 or more years in urban and rural Chinese populations [68]. However, these data may lead to substantial underestimation of the myopia prevalence because refraction data were obtained only from those with visual impairment. In Taiwan, the Shinpai Eye Study in adults aged over 65 years reported that the prevalence of myopia and HM (SD $<-6.0$ D) was $19.4 \%$ and $2.4 \%$, respectively [69]. In Singapore, the prevalence of myopia in Singaporean-Chinese, Malay, and Indians was 38.7\% [66], 26.2\% [70], and $28.0 \%$ [71], and corresponding figures for HM being 9.1\%, 3.9\%, and $4.1 \%$, 
respectively. In Japan, the prevalence of myopia and HM in urban areas is relatively high, $41.8 \%$ and $8.2 \%$, respectively, in 3021 adults above 40 years in the Tajimi Study [72]. However, the myopia rates may be overestimated because of the use of noncycloplegic refraction for the younger population who may have excessive residual accommodation. A latest population-based study from a rural area showed that the prevalence of myopia and HM was $29.5 \%$ and $1.9 \%$, respectively, among adults aged 40 years or older in the Kumejima Study [73]. In this study, the prevalence of myopia was nearly the same as those in urban areas of China, while the prevalence of HM was similar to that reported in rural areas of other Asian countries. In South Korea, the prevalence of myopia and HM was $20.5 \%$ and $1.0 \%$, respectively, among adults above 40 years in the Namil Study [74]. Relatively low prevalence in the study was reflected by rural lesions, it was similar to that of rural Chinese population.

\subsubsection{Rest of East Asian Countries}

In other Asian developing countries, the prevalence of myopia is slightly lower: $17.2 \%$ among adults aged 40 or more years in Mongolia, and $22.1 \%$ among adults aged 30 or more years in Bangladesh $[75,76]$. Further, the myopia rate in the Bangladesh study may be overestimated because of the use of noncycloplegic refraction for the younger group aged 30-39 years who may have excessive residual accommodation. In a rural area in India, the prevalence of myopia and HM was $27.0 \%$ and $3.7 \%$, respectively, in 2508 Indian adults aged above 39 years [77]. Relatively high prevalence in rural Indian population may be caused by higher rates of nuclear cataract. The prevalence of myopia is slightly higher at $36.5 \%$ among adults aged 30 or more years in Pakistan, and at 30.2\% among adults aged 40 or more years in Iran $[78,79]$. The myopia rate in the Pakistan study may be overestimated because of the cohort effect of younger group aged 30-39 years.

\subsubsection{Non-Asian Countries}

In the USA, the latest report in the Chinese American study showed the relatively high prevalence of myopia and HM, 35.1\% and 7.4\%, respectively, in 4144 Chinese adults aged 50 years or older [80]. This result is similar to or slightly higher than same Chinese populations from other studies in urban Asian countries (38.7\% in the Tanjong Pagar Study, Singapore and 32.3\% in the Liwan Eye Study). The Barbados Eye Study reported the prevalence of myopia was $21.9 \%$ in 4709 African-Americans aged 40-84 years [81]. Another population-based study in Latino showed that the overall prevalence of myopia (SE <-1.00 D) and HM in the worse eye was $16.8 \%$ and $2.4 \%$, respectively, among 5927 adults aged 40 years or older [82]. In Europe, although the myopia rate varies across the countries, two latest population-based studies proved that it was nearly the same as those in urban Asian countries. The Gutenburg Health Study in Germany reported that the prevalence of myopia and HM was $35.1 \%$ and 5.6\%, respectively, in 13,959 adults aged 35-74 years. The high prevalence of myopia in the study can be explained by the fact that this cohort had 
younger participants than most other studies [83]. In the Netherlands, the prevalence of myopia was $32.5 \%$ in a total of 3530 adults aged above 46 years in the Rotterdam study [84]. This study may have overestimated the prevalence of myopia because the refraction method was subjective refraction. In UK, a population-based study showed that $23.0 \%$ were myopic among a total of 7444 adults aged above 48 years [85]. In other European countries, the prevalence of myopia is slightly lower: $19.4 \%$ among adults aged 38 or more years in Norway, 19.1\% among adults aged 76 or more years in France, and 14.2\% among adults aged 60 or more years in Greece [84]. In Australia, the prevalence of myopia was relatively lower, 15.0\% in 3654 adults aged over 49 years in the Blue Mountain Eye Study in 1999 [86]. In the two population-based studies, the lowest prevalence appears to be in Africa. In Nigeria, the prevalence of myopia and HM was $16.1 \%$ and $2.1 \%$, respectively, among 13,599 adults aged over 40 years as per the Nigeria National Blindness and Visual Impairment Study [87]. In South Africa, the prevalence of myopia was $11.4 \%$ in 1939 adults aged over 35 years [88]. In the same vein, the prevalence of myopia was relatively low $14.4 \%$ among adults aged 35-55 years in MIROR Study in Colombia [89].

\subsubsection{Generational Gap}

There is a difference in myopia and HM prevalence among age groups. In general, the generational differences of prevalence of myopia and HM are seen with the highest rates in young adults and the lowest rates in older adults. We have shown the higher prevalence rates of myopia (65.5-96.5\%) and HM (14.7-21.6\%) in East Asian young adults in the previous section $[8,57,58]$. By contrast, the lower prevalence rates of myopia (approximately 25-40\%) and HM (2.4-8.2\%) were reported among East Asian middle-aged and elderly adults [69, 72, 90]. Particularly, the burden of HM is important because HM is more likely to develop PM changes that tend to be visually disabling. Some studies supported the idea of two types of HM, one is related to educational parameters such as near-work and frequent among young adults, and the other is more likely related to the earlier onset of myopia by genetic factors in contrast to environmental factors and occurs in older adults [91, 92]. Jonas et al. compared highly myopic young individuals and highly myopic adult individuals and assessed the association of the prevalence of HM with parameters of education. It revealed that education-related parameters did not show a clear association with HM in older generation, while in contrast, HM in school children showed a strong association with education [91]. Thus, it has been assumed that the development of pathologic myopia (PM) in later life may be different depending on two forms of HM with different etiologies. One form of HM is caused by mutations of genes responsible to scleral modeling and leading to abnormal deformity and thin sclera [93], while the other form caused by insufficient outdoor time in younger adults may be driven by reduced release of retinal dopamine [1]. 
In summary, the higher prevalence rates of myopia were also seen in urban East Asian countries (approximately 25-40\%) and in Western Europe or the United States (approximately 20-35\%), compared to other developing Asian countries and some countries in Western populations such as Australia (approximately 15-20\%). Similarly, urban Asian countries have higher prevalence rates of HM (5-9\%), compared with other Asian countries (2-5\%) or non-Asian countries (2-7\%). However, the geographic difference of myopia prevalence in older populations is not pronounced compared to that in younger populations. From a viewpoint of ethnicity difference, Chinese have a substantially higher prevalence of myopia compared with other racial groups, and a similar pattern of even greater magnitude was seen in HM prevalence. The prevalence of myopia and HM in Chinese ethnicity in western countries is similar to other studies of Chinese in urban Asian countries [80].

\subsection{The Prevalence of PM}

Pathologic myopia (PM) has been reported as one of the most common causes of blindness worldwide. Studies reported that PM is the major cause of blindness or visual impairment (VI) in 7\% in Western populations and in $12-27 \%$ in Asian populations [94-99]. According to a review to estimate blindness and VI with myopic macular degeneration (MMD), 10.0 million people had VI from MMD (0.13\%), 3.3 million of whom were blind $(0.04 \%)$ in 2015 , and furthermore 55.7 million people will have VI from MMD $(0.33 \%), 18.5$ million of whom will be blind $(0.19 \%)$ in 2050 [100].

Before we discuss the prevalence of PM in detail, it must be noted that the definition of PM has been inconsistent in previous studies. Avila et al. proposed a definition of myopic maculopathy that included posterior staphyloma, and it has been used most frequently in earlier studies [101]. However, this classification was not based on the actual progression pattern. In 2015, the META-analysis for Pathologic Myopia (META-PM) study group proposed a new classification system for PM for use in future studies [102]. In this classification, myopic macular degeneration (MMD) is categorized into 5 categories according to severity: no myopic retinal lesions (category 0); tessellated fundus only (category 1); diffuse chorioretinal atrophy (category 2); patchy chorioretinal atrophy (category 3); and macula atrophy (category 4). And three additional lesions of MMD that cause central vision loss were included as plus sign: lacquer cracks, myopic choroidal neovascularization (CNV), Fuchs spot. PM is defined if an eye has category 2 or above, or presence of plus sign, or the presence of posterior staphyloma. We summarized populationbased studies on PM prevalence in adult populations (Fig. 2.2).

In China, the Beijing Eye Study showed a high PM prevalence, 3.1\%, among 4319 Chinese subjects aged 40 years or older [103]. PM was defined with myopic chorioretinal atrophy or staphyloma or lacquer cracks or Fuch's spot. In the same definition, the Handan Eye Study showed that the prevalence of PM and HM was $0.9 \%$ and $2.1 \%$, respectively, among 6603 Chinese subjects aged 30 years or older 


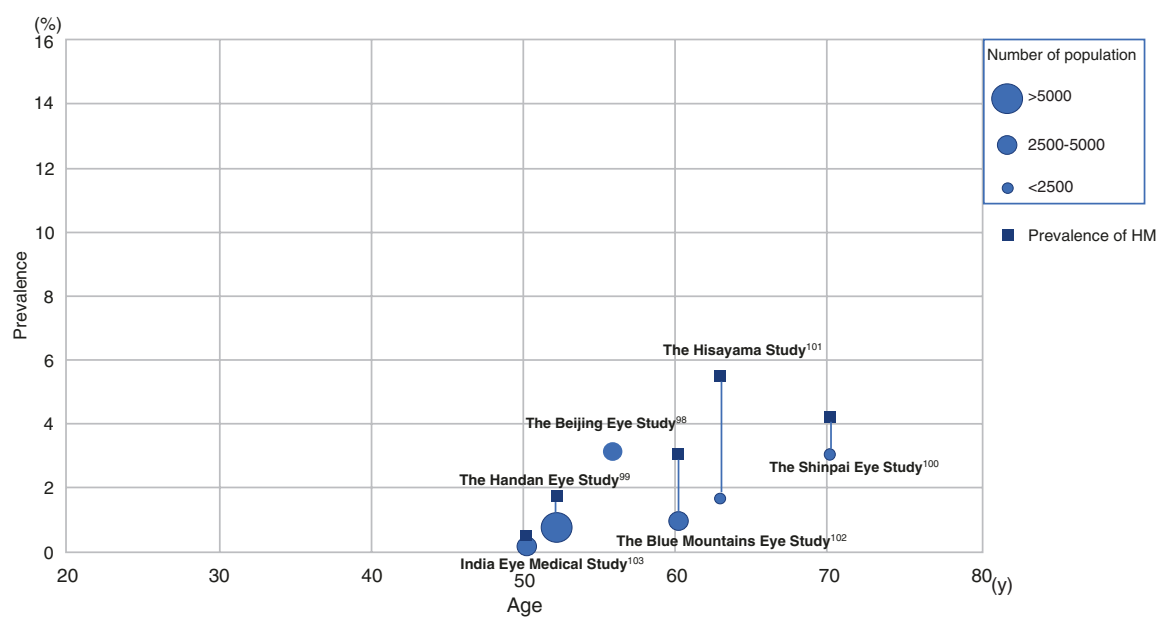

Fig. 2.2 Prevalence of pathologic myopia (PM) among adults in population-based studies

[104]. The much lower prevalence in this study than Beijing might be due to urban and rural differences. Among 1058 Taiwanese subjects aged 65 years or older in the Shinpai Eye study, the prevalence of PM and HM was 3\% and 4.2\%, respectively, with the definition by Avila et al. [105]. The high prevalence was influenced by its older population than other population-based studies. The Hisayama study reported the prevalence of PM and $\mathrm{HM}$ was $1.7 \%$ and $5.7 \%$, respectively, among 1892 Japanese aged 40 years or older with the definition of PM as myopic chorioretinal atrophy, lacquer cracks, or Fuch's spot [106]. However, this study cannot exclude the possibility of sampling bias because the response rate was only $44.4 \%$. In Western countries, the Blue Mountain Eye Study was performed in 3583 adults aged 49 years or older, who were mainly White urban population of Australia, using the same PM definition with two studies in China [107]. The prevalence of PM and HM was $1.2 \%$ and $2.7 \%$, respectively. Using the new META-PM classification, the prevalence of PM and HM was $0.2 \%$ and $0.5 \%$, respectively, among 4561 Indian subjects aged 30 years or older in rural central India [108]. However, the population in this study may not be adequately representative of the whole population of India because this study was conducted in rural tribal regions.

As shown above, the prevalence of PM among adult populations was relatively low in the world. Furthermore, the prevalence of PM among middle-aged and elderly adults is higher in urban East Asian populations (1.7-3.1\%) than rural Asian populations $(0.2-0.9 \%)$ and non-Asian populations (1.2\%) [109]. It is consistent with the results of higher prevalence of HM in East Asian countries because the risk of PM increases with HM [109]. Both the prevalence and severity of PM become higher in adult population aged 40 years and with severe high myopia. Compared to the PM prevalence in adult populations, adolescents and children have significantly lower prevalence [27, 110]. It supports the idea that myopic macular changes are time-dependent changes as a result of mechanical stretching of the retina from axial elongation. However, a recent report revealed that myopia-related changes of the optic disc and macula were commonly found in highly myopic eyes in young adults [111]. 
Thus, the disease burden of PM due to high myopia is likely to increase in future, contributed by the aging effect where young adults who have high rates of high myopia will grow older.

\subsection{Conclusion}

In children, the prevalence of myopia is substantially higher in urban East Asian countries (49.7-62.0\% among 12-year-old children) compared with other countries (6.0-20.0\% among 12-year-old children). Similarly, in teenagers and young adults, the prevalence of myopia is higher in East Asian countries (65.5-96.5\%) compared with other countries (12.8-35.0\%). However, the geographic difference of myopia prevalence in older populations is less than that of younger populations. The prevalence rates of myopia in adults in urban East Asian countries are only slightly higher than in Western countries.

A relationship between myopia prevalence and community development is apparent, and most data have shown urban areas have a higher prevalence of myopia than rural areas. The association of an urbanized environment with myopia development in Asia could be mediated by factors such as intensive education and greater levels of near-work and less outdoor time. Overall, the prevalence of myopia in child population seems to be strongly related to the region where they grow up and the environmental factors such as urbanization, economy, and education.

Generational differences are seen with the highest rates in young adults (myopia 65.5-96.5\% and HM 6.8-21.6\%) and the lowest rates in older adults (myopia 25.0-40.0\% and HM 2.4-8.2\%). The disease progression pattern of HM and subsequent development of PM may be different between young adults and older adults due to generational differences, or changes in the lifestyle factors such as the education system and near-work and outdoor time exposure in rapidly developing urban Asian countries.

Current data show a relatively low prevalence of PM among middle-aged and elderly adults so far, and PM increases with age over 40 years and severity of myopia. Despite the relatively low prevalence in general population, PM is the major cause of blindness or visual impairment in both Asian populations and Western populations. According to a previous study, early grades of PM lesions are observed in young highly myopic adults in urban Asian population, and these structure changes are likely to worsen with age [111]. Considering the increasing prevalence of HM among young generations, we must be prepared for the expected increase of disease burden of PM in the near future.

\section{References}

1. Dolgin E. The myopia boom. Nature. 2015;519(7543):276-8.

2. Vitale $S$, Cotch MF, Sperduto RD. Prevalence of visual impairment in the United States. JAMA. 2006;295(18):2158-63.

3. Zheng YF, Pan CW, Chay J, Wong TY, Finkelstein E, Saw SM. The economic cost of myopia in adults aged over 40 years in Singapore. Invest Ophthalmol Vis Sci. 2013;54(12):7532-7. 
4. Liang YB, Wong TY, Sun LP, Tao QS, Wang JJ, Yang XH, et al. Refractive errors in a rural Chinese adult population the Handan eye study. Ophthalmology. 2009;116(11):2119-27.

5. Morgan IG, Ohno-Matsui K, Saw S-M. Myopia. Lancet. 2012;379(9827):1739-48.

6. Morgan IG. What public policies should be developed to deal with the epidemic of myopia? Optom Vis Sci. 2016;93(9):1058-60.

7. Lin LL, Shih YF, Hsiao CK, Chen CJ. Prevalence of myopia in Taiwanese school children: 1983 to 2000. Ann Acad Med. 2004;33(1):27-33.

8. Jung SK, Lee JH, Kakizaki H, Jee D. Prevalence of myopia and its association with body stature and educational level in 19-year-old male conscripts in Seoul, South Korea. Invest Ophthalmol Vis Sci. 2012;53(9):5579-83.

9. Holden BA, Fricke TR, Wilson DA, Jong M, Naidoo KS, Sankaridurg P, et al. Global prevalence of myopia and high myopia and temporal trends from 2000 through 2050. Ophthalmology. 2016;123(5):1036-42.

10. Wong TY, Ferreira A, Hughes R, Carter G, Mitchell P. Epidemiology and disease burden of pathologic myopia and myopic choroidal neovascularization: an evidence-based systematic review. Am J Ophthalmol. 2014;157(1):9-25.e12.

11. Zhao J, Mao J, Luo R, Li F, Pokharel GP, Ellwein LB. Accuracy of noncycloplegic autorefraction in school-age children in China. Optom Vis Sci. 2004;81(1):49-55.

12. Fotedar R, Rochtchina E, Morgan I, Wang JJ, Mitchell P, Rose KA. Necessity of cycloplegia for assessing refractive error in 12-year-old children: a population-based study. Am J Ophthalmol. 2007;144(2):307-9.

13. Saw SM, Tong L, Chua WH, Chia KS, Koh D, Tan DT, et al. Incidence and progression of myopia in Singaporean school children. Invest Ophthalmol Vis Sci. 2005;46(1):51-7.

14. Fan DS, Lam DS, Lam RF, Lau JT, Chong KS, Cheung EY, et al. Prevalence, incidence, and progression of myopia of school children in Hong Kong. Invest Ophthalmol Vis Sci. 2004;45(4):1071-5.

15. He M, Zeng J, Liu Y, Xu J, Pokharel GP, Ellwein LB. Refractive error and visual impairment in urban children in Southern China. Invest Ophthalmol Vis Sci. 2004;45(3):793-9.

16. Zadnik K. The Glenn A. Fry Award Lecture (1995). Myopia development in childhood. Optom Vis Sci. 1997;74(8):603-8.

17. O'Donoghue L, Kapetanankis VV, McClelland JF, Logan NS, Owen CG, Saunders KJ, et al. Risk factors for childhood myopia: findings from the NICER study. Invest Ophthalmol Vis Sci. 2015;56(3):1524-30.

18. Ip JM, Huynh SC, Robaei D, Kifley A, Rose KA, Morgan IG, et al. Ethnic differences in refraction and ocular biometry in a population-based sample of 11-15-year-old Australian children. Eye. 2008;22(5):649-56.

19. Murthy GV, Gupta SK, Ellwein LB, Munoz SR, Pokharel GP, Sanga L, et al. Refractive error in children in an urban population in New Delhi. Invest Ophthalmol Vis Sci. 2002;43(3): 623-31.

20. Sapkota YD, Adhikari BN, Pokharel GP, Poudyal BK, Ellwein LB. The prevalence of visual impairment in school children of upper-middle socioeconomic status in Kathmandu. Ophthalmic Epidemiol. 2008;15(1):17-23.

21. Gao Z, Meng N, Muecke J, Chan WO, Piseth H, Kong A, et al. Refractive error in school children in an urban and rural setting in Cambodia. Ophthalmic Epidemiol. 2012;19(1):16-22.

22. Hsu CC, Huang N, Lin PY, Tsai DC, Tsai CY, Woung LC, et al. Prevalence and risk factors for myopia in second-grade primary school children in Taipei: a population-based study. J Chin Med Assoc. 2016;79(11):625-32.

23. Lai YH, Hsu HT, Wang HZ, Chang SJ, Wu WC. The visual status of children ages 3 to 6 years in the vision screening program in Taiwan. J AAPOS. 2009;13(1):58-62.

24. Li Y, Liu J, Qi P. The increasing prevalence of myopia in junior high school students in the haidian district of beijing, china: A 10-year population-based survey. BMC Ophthalmol. 2017;17:88.

25. Ma Y, Qu X, Zhu X, Xu X, Zhu J, Sankaridurg P, et al. Age-specific prevalence of visual impairment and refractive error in children aged 3-10 years in Shanghai, China. Invest Ophthalmol Vis Sci. 2016;57(14):6188-96. 
26. Lee JH, Jee D, Kwon JW, Lee WK. Prevalence and risk factors for myopia in a rural Korean population. Invest Ophthalmol Vis Sci. 2013;54(8):5466-71.

27. Pi LH, Chen L, Liu Q, Ke N, Fang J, Zhang S, et al. Prevalence of eye diseases and causes of visual impairment in school-aged children in Western China. J Epidemiol. 2012;22(1):37-44.

28. He M, Huang W, Zheng Y, Huang L, Ellwein LB. Refractive error and visual impairment in school children in rural southern china. Ophthalmology. 2007;114:374-82.

29. Zhao J, Pan X, Sui R, Munoz SR, Sperduto RD, Ellwein LB. Refractive error study in children: results from Shunyi District, China. Am J Ophthalmol. 2000;129(4):427-35.

30. Fan DS, Lai C, Lau HH, Cheung EY, Lam DS. Change in vision disorders among Hong Kong preschoolers in 10 years. Clin Exp Ophthalmol. 2011;39(5):398-403.

31. Dirani M, Chan YH, Gazzard G, Hornbeak DM, Leo SW, Selvaraj P, et al. Prevalence of refractive error in Singaporean Chinese children: the strabismus, amblyopia, and refractive error in young Singaporean Children (STARS) study. Invest Ophthalmol Vis Sci. 2010;51(3):1348-55.

32. Dandona R, Dandona L, Srinivas M, Giridhar P, McCarty CA, Rao GN. Population-based assessment of refractive error in India: the Andhra Pradesh eye disease study. Clin Exp Ophthalmol. 2002;30(2):84-93.

33. Yekta A, Fotouhi A, Hashemi H, Dehghani C, Ostadimoghaddam H, Heravian J, et al. Prevalence of refractive errors among schoolchildren in Shiraz, Iran. Clin Exp Ophthalmol. 2010;38(3):242-8.

34. Jamali P, Fotouhi A, Hashemi H, Younesian M, Jafari A. Refractive errors and amblyopia in children entering school: Shahrood, iran. Optom Vis Sci. 2009;86:364-9.

35. Fotouhi A, Hashemi H, Khabazkhoob M, Mohammad K. The prevalence of refractive errors among schoolchildren in Dezful, Iran. Br J Ophthalmol. 2007;91(3):287-92.

36. Hashemi H, Fotouhi A, Mohammad K. The age- and gender-specific prevalences of refractive errors in Tehran: the Tehran Eye Study. Ophthalmic Epidemiol. 2004;11(3):213-25.

37. Yingyong P. Refractive errors survey in primary school children (6-12 year old) in 2 provinces: Bangkok and Nakhonpathom (one year result). J Med Assoc Thail. 2010;93(10):1205-10.

38. Wen G, Tarczy-Hornoch K, McKean-Cowdin R, Cotter SA, Borchert M, Lin J, et al. Prevalence of myopia, hyperopia, and astigmatism in non-Hispanic white and Asian children: multi-ethnic pediatric eye disease study. Ophthalmology. 2013;120(10):2109-16.

39. Giordano L, Friedman DS, Repka MX, Katz J, Ibironke J, Hawes P, et al. Prevalence of refractive error among preschool children in an urban population: the Baltimore Pediatric Eye Disease Study. Ophthalmology. 2009;116(4):739-46.

40. Tideman JWL, Polling JR, Hofman A, Jaddoe VW, Mackenbach JP, Klaver CC. Environmental factors explain socioeconomic prevalence differences in myopia in 6-year-old children. $\mathrm{Br} \mathrm{J}$ Ophthalmol. 2018;102(2):243-7.

41. Logan NS, Shah P, Rudnicka AR, Gilmartin B, Owen CG. Childhood ethnic differences in ametropia and ocular biometry: the Aston Eye Study. Ophthalmic Physiol Opt. 2011;31(5):550-8.

42. O'Donoghue L, McClelland JF, Logan NS, Rudnicka AR, Owen CG, Saunders KJ. Refractive error and visual impairment in school children in northern ireland. $\mathrm{Br} \mathrm{J}$ Ophthalmol. 2010;94:1155-9.

43. Czepita D, Zejmo M, Mojsa A. Prevalence of myopia and hyperopia in a population of polish school children. Ophthalmic Physiol Opt. 2007;27(1):60-5.

44. French AN, Morgan IG, Burlutsky G, Mitchell P, Rose KA. Prevalence and 5- to 6-year incidence and progression of myopia and hyperopia in Australian school children. Ophthalmology. 2013;120(7):1482-91.

45. Ojaimi E, Rose KA, Morgan IG, Smith W, Martin FJ, Kifley A, et al. Distribution of ocular biometric parameters and refraction in a population-based study of Australian children. Invest Ophthalmol Vis Sci. 2005;46(8):2748-54.

46. Kumah BD, Ebri A, Abdul-Kabir M, Ahmed AS, Koomson NY, Aikins S, et al. Refractive error and visual impairment in private school children in Ghana. Optom Vis Sci. 2013;90(12):1456-61.

47. Naidoo KS, Raghunandan A, Mashige KP, Govender P, Holden BA, Pokharel GP, Ellwein LB. Refractive error and visual impairment in african children in south africa. Invest Ophthalmol Vis Sci. 2003;44:3764-70. 
48. Goh PP, Abqariyah Y, Pokharel GP, Ellwein LB. Refractive error and visual impairment in school-age children in Gombak District, Malaysia. Ophthalmology. 2005;112(4):678-85.

49. Li Z, Xu K, Wu S, Lv J, Jin D, Song Z, et al. Population-based survey of refractive error among school-aged children in rural northern China: the Heilongjiang eye study. Clin Exp Ophthalmol. 2014;42(4):379-84.

50. Saw SM, Carkeet A, Chia KS, Stone RA, Tan DT. Component dependent risk factors for ocular parameters in Singapore Chinese children. Ophthalmology. 2002;109(11):2065-71.

51. Rose KA, Morgan IG, Smith W, Burlutsky G, Mitchell P, Saw SM. Myopia, lifestyle, and schooling in students of Chinese ethnicity in Singapore and Sydney. Arch Ophthalmol. 2008;126(4):527-30.

52. Rudnicka AR, Kapetanakis VV, Wathern AK, Logan NS, Gilmartin B, Whincup PH, et al. Global variations and time trends in the prevalence of childhood myopia, a systematic review and quantitative meta-analysis: implications for aetiology and early prevention. $\mathrm{Br} \mathrm{J}$ Ophthalmol. 2016;100(7):882-90.

53. Ding BY, Shih YF, Lin LLK, Hsiao CK, Wang IJ. Myopia among schoolchildren in East Asia and Singapore. Surv Ophthalmol. 2017;62(5):677-97.

54. Chen M, Wu A, Zhang L, Wang W, Chen X, Yu X, et al. The increasing prevalence of myopia and high myopia among high school students in Fenghua city, eastern China: a 15-year population-based survey. BMC Ophthalmol. 2018;18(1):159.

55. Wu JF, Bi HS, Wang SM, Hu YY, Wu H, Sun W, et al. Refractive error, visual acuity and causes of vision loss in children in Shandong, China. The Shandong Children Eye Study. PLoS One. 2013;8(12):e82763.

56. Sun J, Zhou J, Zhao P, Lian J, Zhu H, Zhou Y, et al. High prevalence of myopia and high myopia in 5060 Chinese university students in Shanghai. Invest Ophthalmol Vis Sci. 2012;53(12):7504-9.

57. Lee YY, Lo CT, Sheu SJ, Lin JL. What factors are associated with myopia in young adults? A survey study in Taiwan Military Conscripts. Invest Ophthalmol Vis Sci. 2013;54(2):1026-33.

58. Koh V, Yang A, Saw SM, Chan YH, Lin ST, Tan MM, et al. Differences in prevalence of refractive errors in young Asian males in Singapore between 1996-1997 and 2009-2010. Ophthalmic Epidemiol. 2014;21(4):247-55.

59. Bar Dayan Y, Levin A, Morad Y, Grotto I, Ben-David R, Goldberg A, et al. The changing prevalence of myopia in young adults: a 13-year series of population-based prevalence surveys. Invest Ophthalmol Vis Sci. 2005;46(8):2760-5.

60. McKnight CM, Sherwin JC, Yazar S, Forward H, Tan AX, Hewitt AW, et al. Myopia in young adults is inversely related to an objective marker of ocular sun exposure: the Western Australian Raine cohort study. Am J Ophthalmol. 2014;158(5):1079-85.

61. Jacobsen N, Jensen H, Goldschmidt E. Prevalence of myopia in Danish conscripts. Acta Ophthalmol Scand. 2007;85(2):165-70.

62. Midelfart A, Kinge B, Midelfart S, Lydersen S. Prevalence of refractive errors in young and middle-aged adults in Norway. Acta Ophthalmol Scand. 2002;80(5):501-5.

63. Sperduto RD, Seigel D, Roberts J, Rowland M. Prevalence of myopia in the United States. Arch Ophthalmol. 1983;101(3):405-7.

64. Mimouni M, Zoller L, Horowitz J, Wygnanski-Jaffe T, Morad Y, Mezer E. Cycloplegic autorefraction in young adults: is it mandatory? Graefes Arch Clin Exp Ophthalmol. 2016;254(2):395-8.

65. Wang Q, Klein BE, Klein R, Moss SE. Refractive status in the Beaver Dam Eye Study. Invest Ophthalmol Vis Sci. 1994;35(13):4344-7.

66. Wong TY, Foster PJ, Hee J, Ng TP, Tielsch JM, Chew SJ, et al. Prevalence and risk factors for refractive errors in adult Chinese in Singapore. Invest Ophthalmol Vis Sci. 2000;41(9):2486-94.

67. He M, Huang W, Li Y, Zheng Y, Yin Q, Foster PJ. Refractive error and biometry in older Chinese adults: the Liwan eye study. Invest Ophthalmol Vis Sci. 2009;50(11):5130-6.

68. Xu L, Li J, Cui T, Hu A, Fan G, Zhang R, et al. Refractive error in urban and rural adult Chinese in Beijing. Ophthalmology. 2005;112(10):1676-83.

69. Cheng CY, Hsu WM, Liu JH, Tsai SY, Chou P. Refractive errors in an elderly Chinese population in Taiwan: the Shihpai Eye Study. Invest Ophthalmol Vis Sci. 2003;44(11):4630-8. 
70. Saw SM, Chan YH, Wong WL, Shankar A, Sandar M, Aung T, et al. Prevalence and risk factors for refractive errors in the Singapore Malay Eye Survey. Ophthalmology. 2008;115(10):1713-9.

71. Pan CW, Wong TY, Lavanya R, Wu RY, Zheng YF, Lin XY, et al. Prevalence and risk factors for refractive errors in Indians: the Singapore Indian Eye Study (SINDI). Invest Ophthalmol Vis Sci. 2011;52(6):3166-73.

72. Sawada A, Tomidokoro A, Araie M, Iwase A, Yamamoto T. Refractive errors in an elderly Japanese population: the Tajimi study. Ophthalmology. 2008;115(2):363-70.e3.

73. Nakamura Y, Nakamura Y, Higa A, Sawaguchi S, Tomidokoro A, Iwase A, et al. Refractive errors in an elderly rural Japanese population: the Kumejima study. PLoS One. 2018;13(11):e0207180.

74. Yoo YC, Kim JM, Park KH, Kim CY, Kim TW. Refractive errors in a rural Korean adult population: the Namil Study. Eye. 2013;27(12):1368-75.

75. Wickremasinghe S, Foster PJ, Uranchimeg D, Lee PS, Devereux JG, Alsbirk PH, et al. Ocular biometry and refraction in Mongolian adults. Invest Ophthalmol Vis Sci. 2004;45(3):776-83.

76. Bourne RR, Dineen BP, Ali SM, Noorul Huq DM, Johnson GJ. Prevalence of refractive error in Bangladeshi adults: results of the national blindness and low vision survey of Bangladesh. Ophthalmology. 2004;111(6):1150-60.

77. Raju P, Ramesh SV, Arvind H, George R, Baskaran M, Paul PG, et al. Prevalence of refractive errors in a rural South Indian population. Invest Ophthalmol Vis Sci. 2004;45(12):4268-72.

78. Shah SP, Jadoon MZ, Dineen B, Bourne RR, Johnson GJ, Gilbert CE, et al. Refractive errors in the adult pakistani population: the national blindness and visual impairment survey. Ophthalmic Epidemiol. 2008;15(3):183-90.

79. Hashemi H, Khabazkhoob M, Jafarzadehpur E, Yekta AA, Emamian MH, Shariati M, et al. High prevalence of myopia in an adult population, Shahroud, Iran. Optom Vis Sci. 2012;89(7):993-9.

80. Varma R, Torres M, McKean-Cowdin R, Rong F, Hsu C, Jiang X. Prevalence and risk factors for refractive error in adult Chinese Americans: The Chinese American Eye Study. Am J Ophthalmol. 2017;175:201-12.

81. Wu SY, Nemesure B, Leske MC. Refractive errors in a black adult population: the Barbados Eye Study. Invest Ophthalmol Vis Sci. 1999;40(10):2179-84.

82. Tarczy-Hornoch K, Ying-Lai M, Varma R. Myopic refractive error in adult Latinos: the Los Angeles Latino Eye Study. Invest Ophthalmol Vis Sci. 2006;47(5):1845-52.

83. Wolfram C, Hohn R, Kottler U, Wild P, Blettner M, Buhren J, et al. Prevalence of refractive errors in the European adult population: the Gutenberg Health Study (GHS). Br J Ophthalmol. 2014;98(7):857-61.

84. Williams KM, Verhoeven VJ, Cumberland P, Bertelsen G, Wolfram C, Buitendijk GH, et al. Prevalence of refractive error in Europe: the European Eye Epidemiology (E(3)) Consortium. Eur J Epidemiol. 2015;30(4):305-15.

85. Sherwin JC, Khawaja AP, Broadway D, Luben R, Hayat S, Dalzell N, et al. Uncorrected refractive error in older British adults: the EPIC-Norfolk Eye Study. Br J Ophthalmol. 2012;96(7):991-6.

86. Attebo K, Ivers RQ, Mitchell P. Refractive errors in an older population: the Blue Mountains Eye Study. Ophthalmology. 1999;106(6):1066-72.

87. Ezelum C, Razavi H, Sivasubramaniam S, Gilbert CE, Murthy GV, Entekume G, et al. Refractive error in Nigerian adults: prevalence, type, and spectacle coverage. Invest Ophthalmol Vis Sci. 2011;52(8):5449-56.

88. Mashige KP, Jaggernath J, Ramson P, Martin C, Chinanayi FS, Naidoo KS. Prevalence of refractive errors in the INK Area, Durban, South Africa. Optom Vis Sci. 2016;93(3): 243-50.

89. Galvis V, Tello A, Otero J, Serrano AA, Gomez LM, Camacho PA, et al. Prevalence of refractive errors in Colombia: MIOPUR study. Br J Ophthalmol. 2018;102(10):1320-3.

90. Pan CW, Zheng YF, Anuar AR, Chew M, Gazzard G, Aung T, et al. Prevalence of refractive errors in a multiethnic Asian population: the Singapore epidemiology of eye disease study. Invest Ophthalmol Vis Sci. 2013;54(4):2590-8. 
91. Jonas JB, Xu L, Wang YX, Bi HS, Wu JF, Jiang WJ, et al. Education-related parameters in high myopia: adults versus school children. PLoS One. 2016;11(5):e0154554.

92. Morgan I, Rose K. How genetic is school myopia? Prog Retin Eye Res. 2005;24(1):1-38.

93. Li YT, Xie MK, Wu J. Association between ocular axial length-related genes and high myopia in a Han Chinese Population. Ophthalmologica. 2016;235(1):57-60.

94. Ohno-Matsui K, Lai TY, Lai CC, Cheung CM. Updates of pathologic myopia. Prog Retin Eye Res. 2016;52:156-87.

95. Cedrone C, Culasso F, Cesareo M, Nucci C, Palma S, Mancino R, et al. Incidence of blindness and low vision in a sample population: the Priverno Eye Study, Italy. Ophthalmology. 2003;110(3):584-8.

96. Klaver CC, Wolfs RC, Vingerling JR, Hofman A, de Jong PT. Age-specific prevalence and causes of blindness and visual impairment in an older population: the Rotterdam Study. Arch Ophthalmol. 1998;116(5):653-8.

97. Iwase A, Araie M, Tomidokoro A, Yamamoto T, Shimizu H, Kitazawa Y. Prevalence and causes of low vision and blindness in a Japanese adult population: the Tajimi Study. Ophthalmology. 2006;113(8):1354-62.

98. Xu L, Wang Y, Li Y, Wang Y, Cui T, Li J, et al. Causes of blindness and visual impairment in urban and rural areas in Beijing: the Beijing Eye Study. Ophthalmology. 2006;113(7):1134. e1-11.

99. Yamada M, Hiratsuka Y, Roberts CB, Pezzullo ML, Yates K, Takano S, et al. Prevalence of visual impairment in the adult Japanese population by cause and severity and future projections. Ophthalmic Epidemiol. 2010;17(1):50-7.

100. Fricke TR, Jong M, Naidoo KS, Sankaridurg P, Naduvilath TJ, Ho SM, et al. Global prevalence of visual impairment associated with myopic macular degeneration and temporal trends from 2000 through 2050: systematic review, meta-analysis and modelling. Br J Ophthalmol. 2018;102(7):855-62.

101. Avila MP, Weiter JJ, Jalkh AE, Trempe CL, Pruett RC, Schepens CL. Natural history of choroidal neovascularization in degenerative myopia. Ophthalmology. 1984;91(12):1573-81.

102. Ohno-Matsui K, Kawasaki R, Jonas JB, Cheung CM, Saw SM, Verhoeven VJ, et al. International photographic classification and grading system for myopic maculopathy. Am J Ophthalmol. 2015;159(5):877-83.e7.

103. Liu HH, Xu L, Wang YX, Wang S, You QS, Jonas JB. Prevalence and progression of myopic retinopathy in Chinese adults: the Beijing Eye Study. Ophthalmology. 2010;117(9):1763-8.

104. Gao LQ, Liu W, Liang YB, Zhang F, Wang JJ, Peng Y, et al. Prevalence and characteristics of myopic retinopathy in a rural Chinese adult population: the Handan Eye Study. Arch Ophthalmol. 2011;129(9):1199-204.

105. Chen SJ, Cheng CY, Li AF, Peng KL, Chou P, Chiou SH, et al. Prevalence and associated risk factors of myopic maculopathy in elderly Chinese: the Shihpai eye study. Invest Ophthalmol Vis Sci. 2012;53(8):4868-73.

106. Asakuma T, Yasuda M, Ninomiya T, Noda Y, Arakawa S, Hashimoto S, et al. Prevalence and risk factors for myopic retinopathy in a Japanese population: the Hisayama Study. Ophthalmology. 2012;119(9):1760-5.

107. Vongphanit J, Mitchell P, Wang JJ. Prevalence and progression of myopic retinopathy in an older population. Ophthalmology. 2002;109(4):704-11.

108. Jonas JB, Nangia V, Gupta R, Bhojwani K, Nangia P, Panda-Jonas S. Prevalence of myopic retinopathy in rural Central India. Acta Ophthalmol. 2017;95(5):e399-404.

109. Wong YL, Saw SM. Epidemiology of pathologic myopia in Asia and worldwide. Asia-Pac J Ophthalmol. 2016;5(6):394-402.

110. Samarawickrama C, Mitchell P, Tong L, Gazzard G, Lim L, Wong TY, et al. Myopia-related optic disc and retinal changes in adolescent children from singapore. Ophthalmology. 2011;118(10):2050-7.

111. Koh V, Tan C, Tan PT, Tan M, Balla V, Nah G, et al. Myopic maculopathy and optic disc changes in highly myopic young asian eyes and impact on visual acuity. Am J Ophthalmol. 2016;164:69-79. 
Open Access This chapter is licensed under the terms of the Creative Commons Attribution 4.0 International License (http://creativecommons.org/licenses/by/4.0/), which permits use, sharing, adaptation, distribution and reproduction in any medium or format, as long as you give appropriate credit to the original author(s) and the source, provide a link to the Creative Commons license and indicate if changes were made.

The images or other third party material in this chapter are included in the chapter's Creative Commons license, unless indicated otherwise in a credit line to the material. If material is not included in the chapter's Creative Commons license and your intended use is not permitted by statutory regulation or exceeds the permitted use, you will need to obtain permission directly from the copyright holder. 